\title{
Upaya Pemurnian Landfill Biogas Menggunakan Metode Adsorben Steel Wool
}

\author{
Muhammad Affan Adhani ${ }^{1 *}$, Ni Ketut Caturwati ${ }^{1,2}$, Imron Rosyadi $^{1}$ \\ *Email corresponding author: $3331170079 @$ gmail.com \\ ${ }^{1}$ Teknik Mesin, Universitas Sultan Ageng Tirtayasa \\ ${ }^{2}$ Laboratorium Konversi Energi, Universitas Sultan Ageng Tirtayasa \\ Jl. Jendral Sudirman Km 3, Kotabumi, Kec. Purwakarta, Kota Cilegon, Banten 42435, Indonesia
}

Article history: Received: 21 Mei 2021 | Revised: 18 Juni 2021 | Accepted: 25 Juni 2021

\begin{abstract}
Biogas calorific value has big impact toward effectiveness of burning. Some methods were involved to increase its calorific value by decreasing the chemical pollutants that were contained in biogas. This research used steel wool as absorbent with its mass variations were 500 gram and 600 gram and biogas flow rate were 1 lpm, 2 lpm, and $3 \mathrm{lpm}$. The aim of this research to determine the increasing percentage of biogas calorific value. The increasing percentage of biogas calorific value after purification can be obtained by using water heating test. The results of this research shown biogas calorific value could be lifted up 36.19\% within variation $600 \mathrm{gr}$ steel wool absorbent and $1 \mathrm{lpm}$ biogas flow rate. Otherwise, variation $500 \mathrm{gr}$ steel wool absorbent and $3 \mathrm{lpm}$ biogas flow rate gave the lowest result which the increasing biogas calorific value was $4.46 \%$. Experiment results showed the increasing number of biogas calorific value will be effective if biogas flow rate is set at low number through the absorbent column and the steel wool mass is set at high number.
\end{abstract}

Keywords - Biogas purification; Calorific value; Steel wool; Water heating test

Abstrak. Nilai kalor yang dimiliki biogas sangat mempengaruhi lamanya proses pembakaran. Beberapa penelitian telah dilakukan untuk meningkatkan nilai kalor yaitu dengan menurunkan kadar zat pengotor yang terkandung bersama biogas. Dalam penelitian ini dilakukan upaya peningkatan nilai kalor biogas dengan menggunakan steel wool sebagai adsorben dengan variasi massa steel wool (500 gram dan 600 gram) dan variasi laju aliran biogas (1 lpm, 2 lpm, dan 3 lpm). Peningkatan nilai kalor biogas sesudah pemurnian ditentukan dengan water heating test. Hasil penelitian menunjukan peningkatan nilai kalor diperoleh pada filter dengan massa adsorben 600 gr dan laju aliran biogas $1 \mathrm{lpm}$, dimana nilai kalor meningkat sebesar 36.19\%. Sedangkan filter dengan 500 gr steel wool adsroben dan laju aliran biogas $3 \mathrm{lpm}$, menghasilkan peningkatan nilai kalor terendah yaitu sebesar $4.46 \%$. Hasil eksperimen menunjukan peningkatan nilai kalor semakin tinggi jika laju aliran biogas makin rendah melalui kolom adsorben dengan massa steel wool yang semakin tinggi.

Kata Kunci - Nilai Kalor; Pemurnian Biogas; Steel wool; Water heating test

\section{Pendahuluan}

Biogas merupakan suatu energi terbarukan dalam bentuk gas yang mudah terbakar (flameable) dan dihasilkan dari reaksi pembusukan bahan - bahan organik (sayuran, sampah organik pasar, kotoran hewan) oleh bakteri bakteri dalam proses anaerob (proses reaksi pembentukan biogas dilakukan dengan minim oksigen) [1]. Biogas yang berasal dari sampah - sampah organik yang berada di tempat pembuangan sampah akhir (TPSA) dapat menghasilkan kandungan metana $\mathrm{CH}_{4}$ lebih dari $40 \%$, nilai tersebut didapatkan setelah dilakukan proses reaksi secara anaerob dalam waktu 10 hari [2]. Air lindi yang dihasilkan dari TPSA Bagendung dapat dimanfaatkan juga untuk menghasilkan biogas, yaitu dengan proses anaerob. Dimana, biogas yang dihasilkan dari air lindi mampu memberikan temperatur maksimum pembakaran sebesar $1027^{\circ} \mathrm{C}$ [3]. Penelitian lain menuliskan bahwa kandungan raw biogas terdiri dari karbon dioksida $\mathrm{CO}_{2} 20.1 \%$, nitrogen $\mathrm{N}_{2} 20.8 \%$, oksigen $\mathrm{O}_{2} 7.1 \%$, dan metana $\mathrm{CH}_{4}$ sebesar $51.1 \%$ [4]. selain gas - gas seperti diatas, gas penyusun lainnya yang terkandung dalam biogas adalah gas hidrogen sulfida $\mathrm{H}_{2} \mathrm{~S}$ sebesar $790 \mathrm{ppm}$ [5]. Salah satu gas yang terkandung pada biogas yaitu gas metana $\mathrm{CH}_{4}$ yang dapat memberikan efek Green House Gases (GHG), mampu menyebabkan global warming sebesar 25 kali lipat dari gas karbon dioksida $\mathrm{CO}_{2}$, dan merupakan sumber antropogenik terbesar setelah tambang batubara [6]. Disamping itu, gas hidrogen sulfida $\mathrm{H}_{2} \mathrm{~S}$ yang terkandung dalam biogas mampu memberikan pengaruh bau yang tidak baik ke lingkungan, beracun dan bersifat korosif yang dapat merusak biogas engine [7].

Berdasarkan literatur tersebut, penelitian ini membahas tentang upaya pemurnian biogas menggunakan adsorben steel wool. Alasan dipilihnya adsorben ini karena bahan yang mudah didapatkan dan memiliki efektivitas penurunan 
kadar hidrogen sulfida sebesar $94 \mp 2 \%$ pada laju aliran raw biogas 1 LPM dengan panjang kolom pemurnian steel wool $100 \mathrm{~cm}$ [8]. Tujuan penelitian ini adalah untuk melihat peningkatan persentase nilai kalor yang dimiliki raw biogas yang terdapat di tempat pembuangan sampah akhir (TPSA) Bagendung kota Cilegon setelah dilakukan pemurnian menggunakan adsorben steel wool dengan menggunakan pengujian water heating test. Adapun manfaat dari penelitian ini untuk meningkatkan nilai kalor yang dimiliki biogas dan mengurangi bau hidrogen sulfida $\mathrm{H}_{2} \mathrm{~S}$ agar biogas ramah lingkungan.

Salah satu cara dalam menentukan nilai kalor biogas yaitu dengan menentukan nilai kalor yang dipindahkan, volume gas yang habis terbakar, dan efisiensi termal sistem panci. Cara tersebut dituliskan dalam metode water heating test (WHT). Dimana, WHT merupakan metode yang digunakan untuk menentukan efisiensi termal panci[9], yang dituliskan sebagai berikut:

Keterangan:

$$
\begin{gathered}
Q_{\text {total }}=\left(m_{\text {cair }} * C_{\text {p cair }} * \Delta T\right)+\left(m_{\text {evaporasi }} * h_{f g}\right) \\
\varepsilon_{\text {Thermal Panci }}=\frac{Q_{\text {total } 1}}{V_{\text {gas }} * \text { CV } 1}
\end{gathered}
$$

$Q_{\text {total } 1}=$ Total perpindahan panas menggunakan bahan bakar raw biogas $(\mathrm{KJ})$

$m_{\text {cair }}=$ massa zat cair $(\mathrm{kg})$

$C p_{\text {cair }}=$ panas spesifik $(\mathrm{KJ} / \mathrm{kgK})$

$\Delta T=$ kenaikan temperatur $\left({ }^{\circ} \mathrm{C}\right)$

$m_{\text {evap }}=$ massa zat cair yang menguap $(\mathrm{kg})$

$h_{f g} \quad=$ Entalphi penguapan $(\mathrm{KJ} / \mathrm{kg})$

$\varepsilon_{\text {thermal }}=$ Efisiensi panas panci

$V_{\text {gas }} \quad=$ volume biogas yang terbakar (l)

$C V_{1} \quad=$ nilai kalor raw biogas $(\mathrm{KJ} / \mathrm{l})$

Dikarenakan dimensi dan material sistem panci yang digunakan dalam semua variasi penelitian adalah sama, maka persamaan rumus 2 dapat dituliskan menjadi:

$$
\begin{aligned}
& C V_{1}=\frac{Q_{\text {total } 1}}{V_{\text {gas }} \varepsilon_{\text {Thermal Panci }}} \\
& C V_{2}=\frac{Q_{\text {total 2 }}}{V_{\text {gas }} \varepsilon_{\text {Thermal Panci }}}
\end{aligned}
$$

Sehingga rumus peningkatan persentase nilai kalor CV biogas setelah dimurnikan menggunakan steel wool adalah sebagai berikut:

$$
\begin{aligned}
& \frac{C V_{2}-C V_{1}}{C V_{1}}=\left(\frac{Q_{\text {total } 2}}{Q_{\text {total } 1}}-1\right) \cdot 100 \% \\
& \frac{C V_{3}-C V_{1}}{C V_{1}}=\left(\frac{Q_{\text {total } 3}}{Q_{\text {total } 1}}-1\right) \cdot 100 \%
\end{aligned}
$$

Keterangan:

$Q_{\text {total 2 }}=$ Total perpindahan panas menggunakan bahan bakar purified biogas 500 gr SW (KJ)

$Q_{\text {total } 3}=$ Total perpindahan panas menggunakan bahan bakar purified biogas $600 \mathrm{gr} \mathrm{SW}(\mathrm{KJ})$

$\mathrm{CV}_{2} \quad=$ nilai kalor purified biogas $500 \mathrm{gr} \mathrm{SW}(\mathrm{KJ} / \mathrm{l})$

$\mathrm{CV}_{3} \quad=$ nilai kalor purified biogas $600 \mathrm{gr} \mathrm{SW}(\mathrm{KJ} / \mathrm{l})$

\section{METODE}

Pada penelitian ini, pengujian divariasikan menjadi 9 variasi pengujian pembakaran yang dilakukan pada kondisi ruangan dengan variable bebas: laju aliran biogas (1, 2, dan 3 LPM) dan massa adsorben steel wool (500 dan 600 gr). Untuk metode pengujian peningkatan persentase nilai kalor biogas yang didapatkan setelah melewati kolom adsorben menggunakan metode water heating test (WHT) mengacu pada ISO 19867-3:2018 [10].

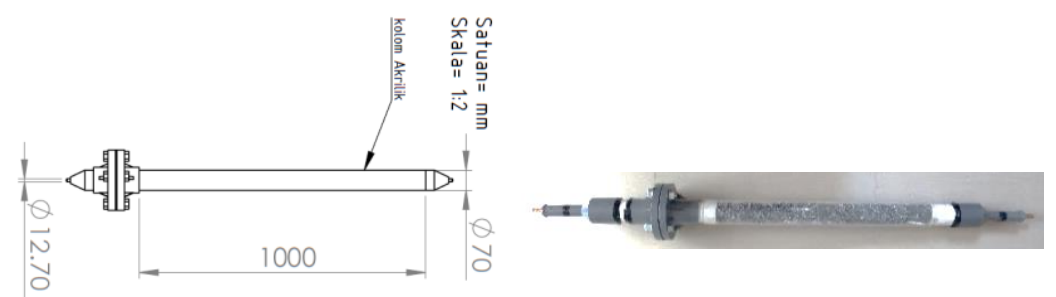

Gambar 1. Kolom tabung akrilik dengan pengisi steel wool 
Adapun alat dan bahan yang digunakan dalam penelitian ini, sebagai berikut:
1. Ban karet dengan kapasitas 40 Liter
9. Mini compressor
2. Ball valve ukuran $1 / 2$ " inch
10. Kompor gas
3. Pipa pvc ukuran $1 / 2$ " dan 2" inch
11. Sistem panci beserta insulasi
4. Nepel selang ukuran $1 / 2$ " inch
12. Probe termokopel
5. Steel Wool 500 gr dan 600 gr
13. Termokopel
6. Selang air ukuran $1 / 2$ " inch
14. Neraca digital
7. Flowmeter skala 1-5 LPM
15. Gelas ukur
8. Kolom akrilik dengan diameter luar $70 \mathrm{~mm}$
16. Flange dengan ketebalan $10 \mathrm{~mm}$ dan panjang 1 meter
17. Reducer pipa PVC 2" ke 1/2”

Sebelum masuk ketahap pengujian WHT, biogas terlebih dahulu dilakukan proses sampling, seperti gambar 2 . Berikut proses sampling raw biogas.

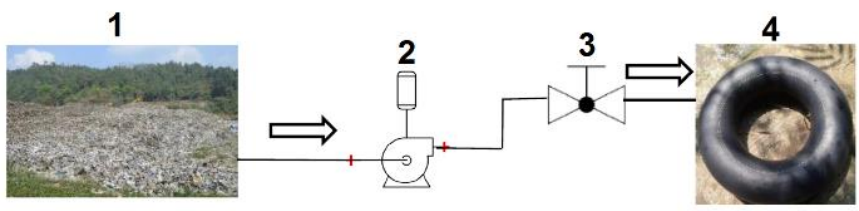

Gambar 2. Proses sampling raw biogas

Keterangan gambar 2, sebagai berikut:

1. Tumpukan sampah - sampah

2. Blower

3. Valve

4. Ban penyimanan biogas

Pada gambar 2, raw biogas yang terpendam ditumpukan sampah - sampah dihisap dengan blower melalui pipa vertikal sedalam $\mp$ 6-7 meter pada tumpukan sampah. Kemudian raw biogas dialiri menuju ban penyimpanan. Dalam melakukan sampling raw biogas tidak perlu menggunakan flow meter karena variasi laju aliran raw biogas 1 , 2, dan 3 LPM yang masuk kedalam ban penyimpanan tidak mengubah komposisi raw biogas tersebut.

Untuk proses sampling purified biogas ditunjukan pada gambar 3. Dimana raw biogas yang terpendam ditumpukan sampah dihisap menggunakan blower lalu dialiri menuju flow meter, pengaturan laju aliran raw biogas diatur menggunakan valve yang terhubung dengan flow meter. Kemudian raw biogas melewati kolom pemurnian yang terdiri dari steel wool. Setelah itu biogas yang sudah dimurnikan (purified biogas) disimpan di dalam ban penyimpanan untuk dilakukan proses WHT.

Hal - hal yang harus diperhatikan dalam proses sampling adalah: pastikan ban penyimpanan yang akan digunakan untuk menyimpan gas selanjutnya sudah dipastikan kosong dan membaca skala flow meter harus sejajar dengan mata, guna menghindari kesalahan pembacaan skala ukur. Keterangan gambar 3, sebagai berikut:
1. Tumpukan sampah - sampah
2. Blower
3. Valve 1
4. Flowmeter
5. Kolom filter akrilik dengan pengisi Steel wool
6. Valve 2
7. Ban penyimpanan biogas

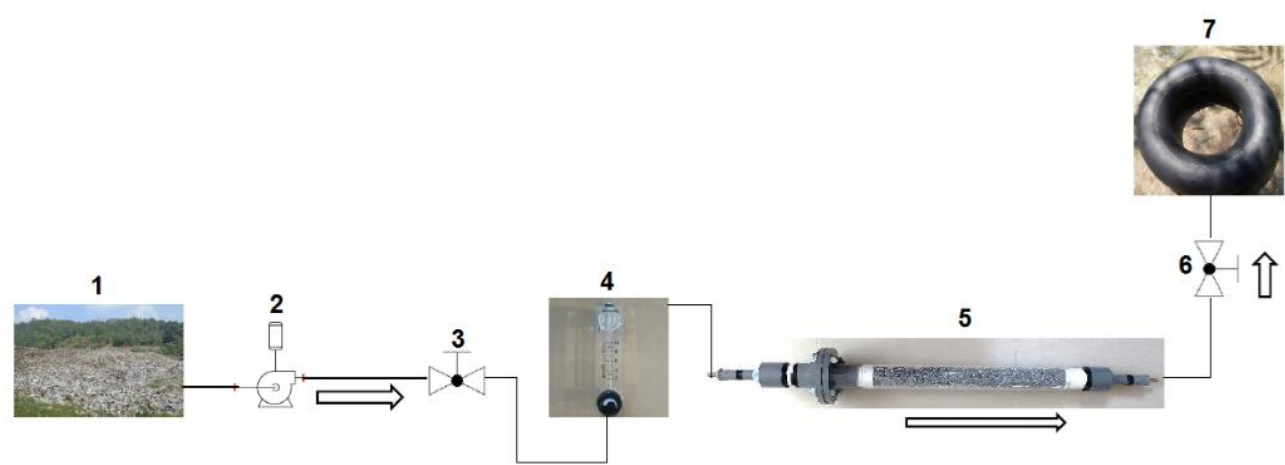

Gambar 3. Proses sampling purified biogas 
Setelah melakukan proses sampling langkah selanjutnya adalah melakukan proses water heating test (WHT). Untuk proses WHT raw biogas dan purified biogas dilakukan dengan cara yang sama. Namun, terlebih dahulu perlu melakukan kalibrasi termokopel yaitu dengan cara menggunakan termokopel untuk mengukur temperatur air pada keadaan mendidih dan mencair (dari es batu ke cair) dalam keadaan standar.

Termokopel yang digunakan dalam penelitian ini menggunakan 2 probe yang dituliskan T1 dan T2. Alasan dilakukannya kalibarasi termokopel karena skala yang terbaca (aktual) bukan skala ideal, hal tersebut disebabkan sirkuit termokopel tidak homogenous sehingga menimbulkan perbedaan nilai pengukuran yang berpotensi menyebabkan error pada proses pengukuran [11]. Maka diperlukan proses kalibrasi untuk memberikan akurasi yang lebih baik.

Tabel 1. Hasil Kalibrasi Termokopel

\begin{tabular}{ccc}
\hline \multicolumn{2}{c}{ Aktual $\left({ }^{\circ} \mathrm{C}\right)$} & Ideal $\left({ }^{\circ} \mathrm{C}\right)$ \\
\hline $\mathrm{T} 1$ & $\mathrm{~T} 2$ & \\
\hline 0.6 & 0.9 & 0 \\
99.6 & 100 & 100 \\
\hline
\end{tabular}

Untuk raw/purified biogas yang sudah disampling, langkah selanjutnya adalah mengaliri raw/purified biogas ke kompor gas untuk dilakukan proses pembakaran. mini compressor digunakan untuk menaikan dan menjaga laju aliran biogas. Laju aliran biogas yang terbaca oleh flow meter pada proses WHT disesuaikan dengan laju aliran biogas ketika proses sampling (contoh: saat melakukan sampling pada variasi 1 LPM dengan adsorben steel wool 600 gr. Maka ketika proses water heating test untuk biogas yang sudah dimurnikan pada variasi seperti diatas, laju alirannya harus dibuat sama yaitu 1 LPM).

Proses water heating test ditunjukan seperti pada gambar 4. Kemudian, biogas dialiri menuju kompor gas untuk dilakukan proses pembakaran yang bertujuan menaikan temperatur air. Volume air yang digunakan pada proses WHT ini adalah 2.5 liter. Kenaikan temperatur air akan terbaca oleh termokopel. Dalam proses pengambilan data temperatur air dengan WHT untuk variasi 1 LPM dan 2 LPM dilakukan selama 15 menit. Namun, untuk pengambilan data temperatur dengan variasi 3 LPM dilakukan selama 13 menit. Nilai temperatur air dicatat setiap 1 menit.

Kemudian ketika sudah mendapatkan hasil kenaikan temperatur air, perhitungan dan analisa dilakukan di $M s$ Excel dengan menggunakan tabel saturated water.

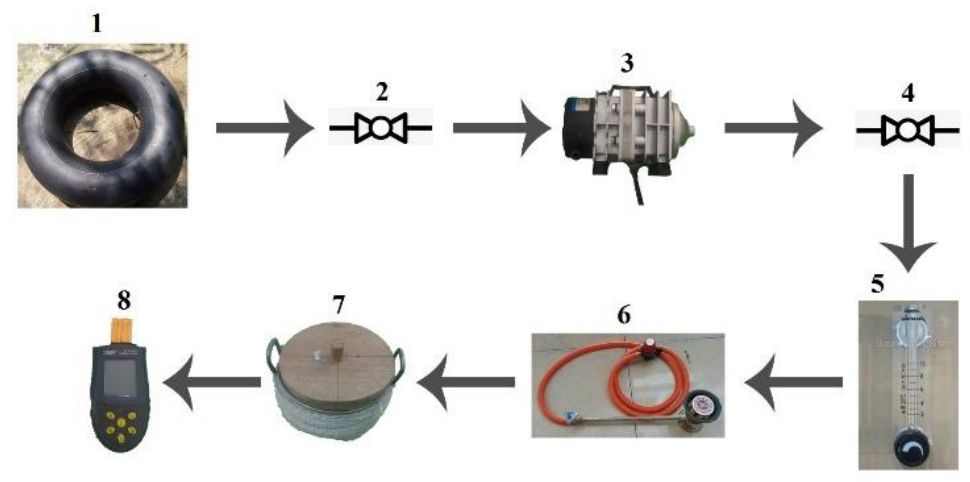

Gambar 4. Proses water heating test

Keterangan Gambar 4, sebagai berikut:

1. Ban karet sebagai tempat penyimpanan raw biogas dan purified biogas

2. Valve 1

3. Mini compressor

4. Valve 2

5. Flow meter

6. Kompor gas

7. System panci dan insulasi panci

8. Termokopel dan probe termokopel 


\section{HASIL DAN PEMBAHASAAN}

Hasil pengukuran temperatur air dengan menggunakan metode water heating test ditunjukan seperti gambar 5, 6, dan 7.

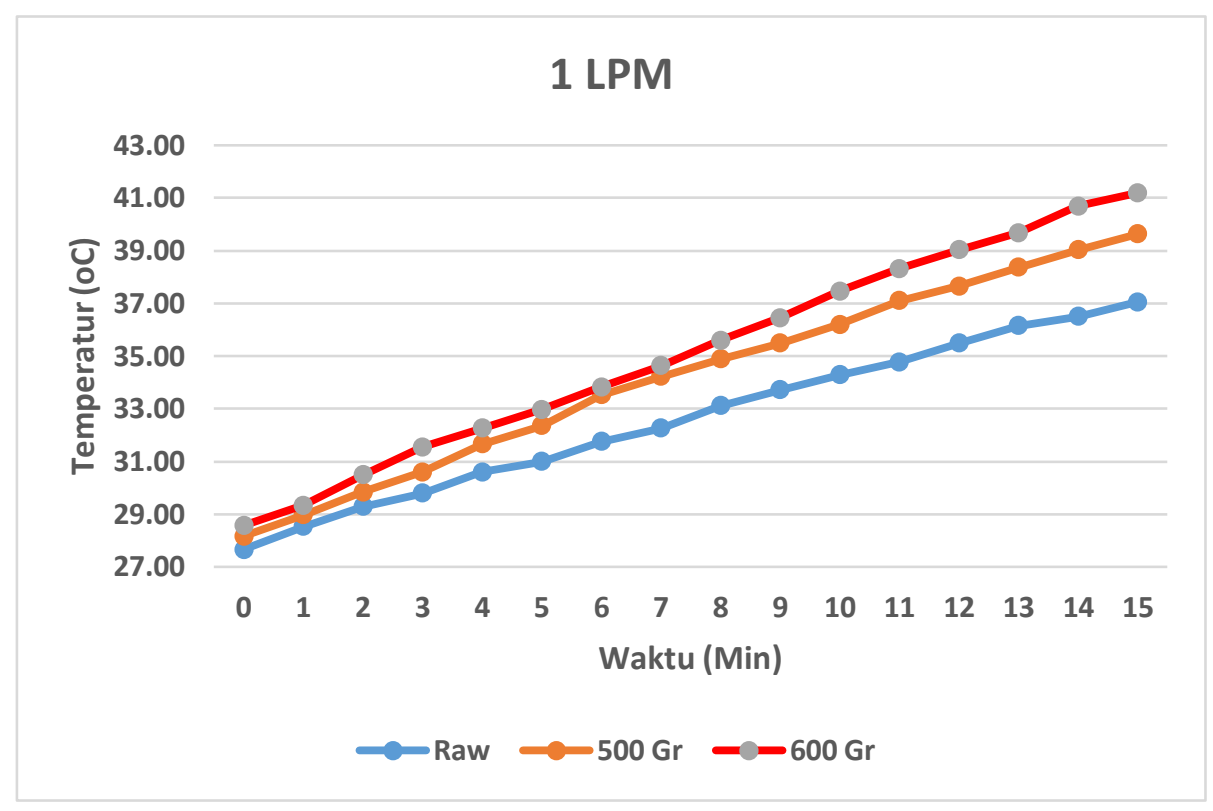

Gambar 5. Grafik peningkatan temperatur terhadap waktu antara raw biogas dan purified biogas dengan filter steel wool 600 gr dan 500 gr pada keadaan laju aliran biogas 1 LPM

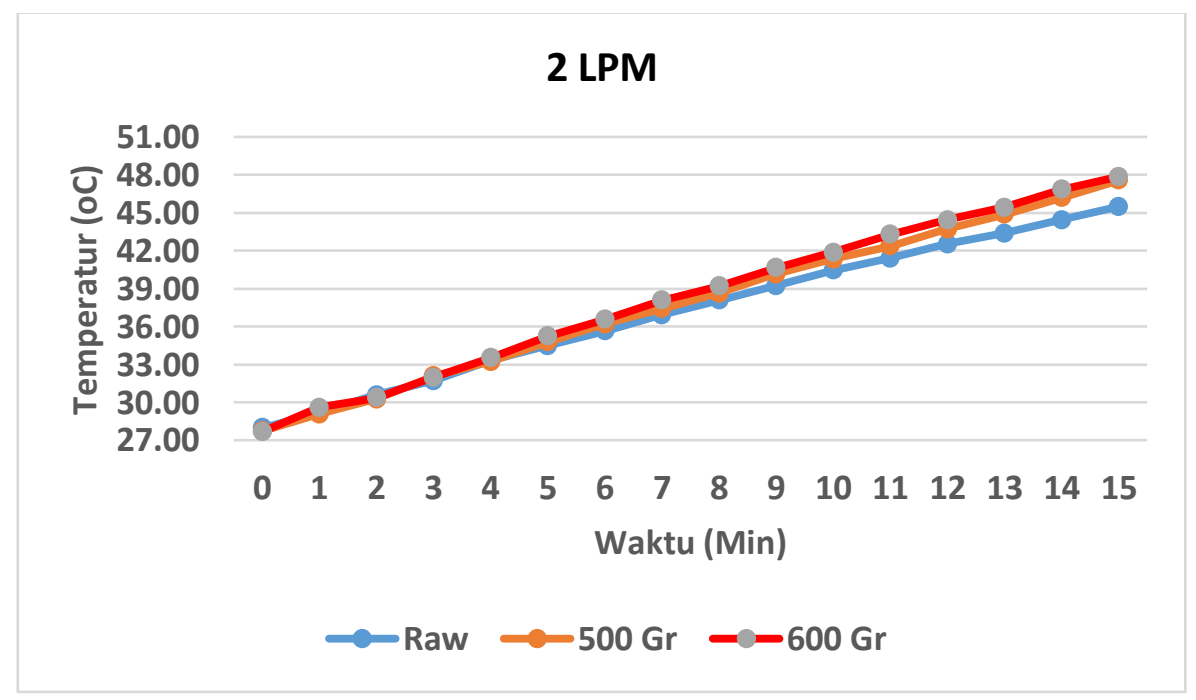

Gambar 6. Grafik peningkatan temperatur terhadap waktu antara raw biogas dan purified biogas dengan filter steel wool 600 gr dan 500 gr pada keadaan laju aliran biogas 2 LPM 


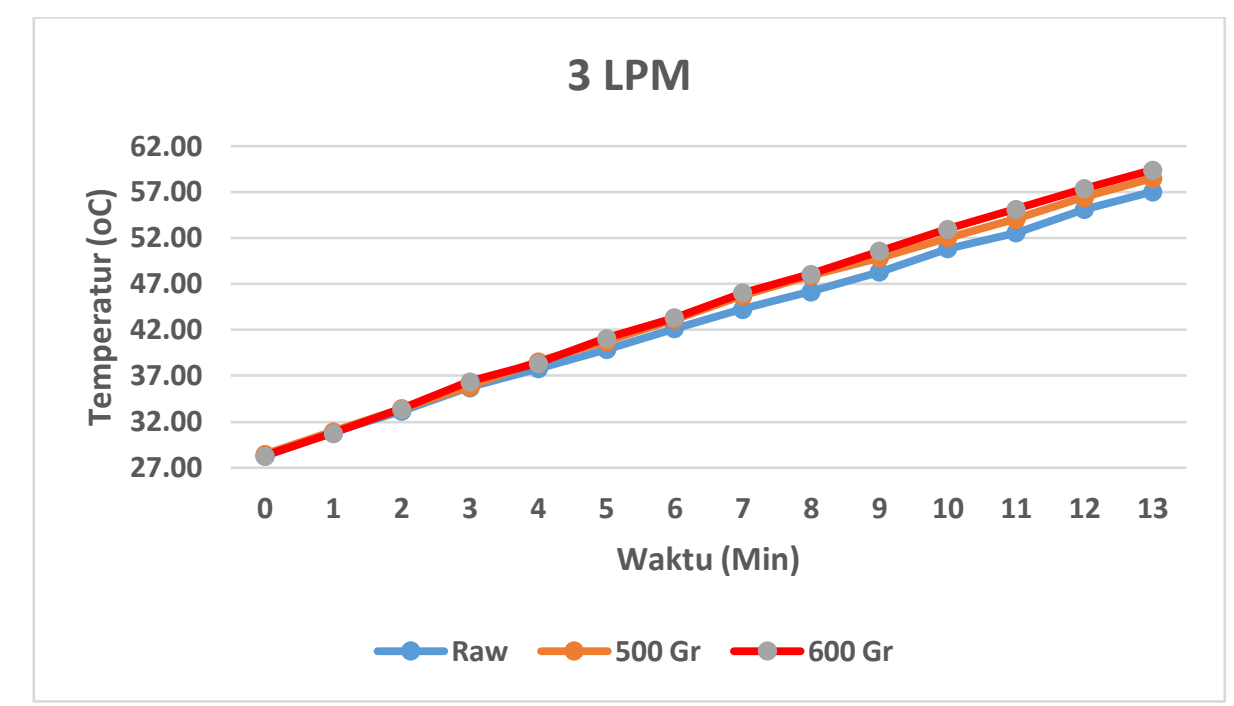

Gambar 7. Grafik peningkatan temperatur terhadap waktu antara raw biogas dan purified biogas dengan filter steel wool 600 gr dan 500 gr pada keadaan laju aliran biogas 3 LPM

Berikut Gambar grafik kenaikan persentase calorific value $(\mathrm{CV})$ biogas.

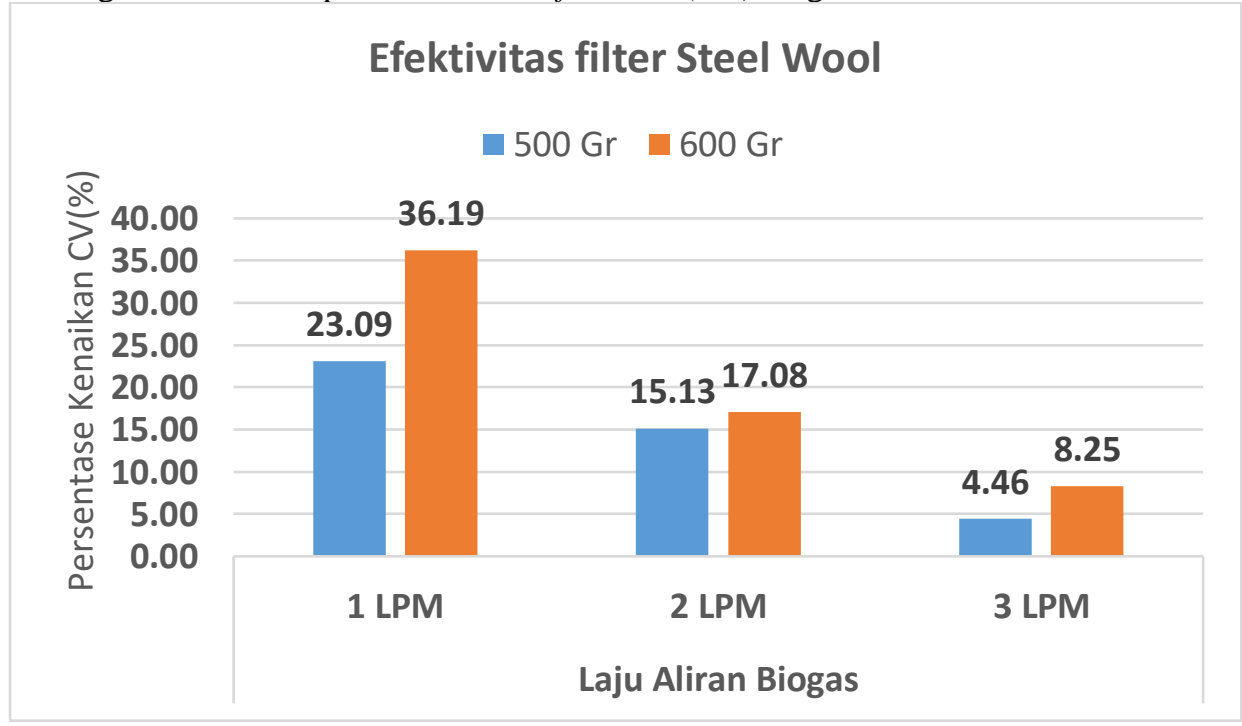

Gambar 8. Persentase kenaikan calorific value biogas setelah dilakukan proses pemurnian dengan menggunakan steel wool

Berdasarkan hasil perhitungan yang diilustrasikan pada gambar 8, menunjukan bahwa semakin kecil nilai laju aliran (LPM) Biogas yang melewati kolom pemurnian dan semakin besar massa adsorben, maka semakin tinggi persentase peningkatan calorific value biogas yang dapat ditingkatkan. Terlihat pada kombinasi adsorben steel wool sebesar 600 gr dengan laju aliran biogas sebesar 1 LPM mampu meningkatkan calorific value biogas sebesar 36.19\%. Hal tersebut disebabkan oleh penurunan kadar karbon dioksida $\mathrm{CO}_{2}$ dan asam sulfida $\mathrm{H}_{2} \mathrm{~S}$ yang terdapat dalam raw biogas, sehingga memberikan beda temperatur antara raw biogas dan purified biogas pada menit ke-15 sebesar $4.14{ }^{\circ} \mathrm{C}$. Penurunan kadar gas $\mathrm{CO}_{2}$ dan $\mathrm{H}_{2} \mathrm{~S}$ yaitu sebesar $\mp 28 \%$ dan $\mp 91 \%$ pada keadaan laju aliran biogas 2 LPM dengan massa adsorben steel wool 500 gr, didapatkan peningkatan kadar gas metana $\mathrm{CH}_{4} \mathrm{sebesar}$ $\mp 7 \%$ [5]. Pada variasi laju aliran 3 LPM dengan massa adsorben 500 gr memiliki persentase kenaikan calorific value yang paling kecil yaitu $4.46 \%$. Hal ini disebabkan waktu kontak antara raw biogas dengan adsorben relatif singkat sehingga penyerapan gas $\mathrm{CO}_{2}$ dan $\mathrm{H}_{2} \mathrm{~S}$ kurang optimal seperti yang ditunjukan oleh gambar 7, dimana beda temperatur antara raw biogas dan purified biogas pada menit ke-13 adalah $1.47^{\circ} \mathrm{C}$. 


\section{KESIMPULAN}

Berdasarkan penelitian yang telah dilakukan maka didapatkan beberapa kesimpulan, sebagai berikut: Peningkatan calorific value paling besar terjadi pada kombinasi absorben steel wool 600 gr dengan laju aliran biogas sebesar 1 LPM yang mampu meningkatkan calorific value biogas sebesar 36.19\%. Semakin kecil nilai laju aliran (LPM) Biogas yang melewati kolom pemurnian dan semakin besar massa absorben, maka semakin tinggi tingkat calorific value biogas yang dapat ditingkatkan. Metode water heating test dapat digunakan untuk menentukan persentase peningkatan nilai kalor yang dimiliki oleh biogas.

\section{UCAPAN TERIMA KASIH}

Terima kasih untuk Lab Konversi Energi Fakultas Teknik Untirta dan TPSA Bagendung atas dukungan yang diberikan sehingga penelitian ini dapat terlaksana dengan baik.

\section{REFERENSI}

[1] A. Pertiwiningrum, Instalasi Biogas, First., vol. 1, no. 1. Yogyakarta: CV. KOLOM CETAK, 2018.

[2] C. N. Ketut, S. Agung, H. Heri, and P. M. Permana, "Time Management of an Anaerobic Solid Waste Digester With Leachate As A Starter To Obtain The Continuous Biogas Production," pp. 1-4, 2017.

[3] C. N. Ketut, S. Agung, P. Mekro, H. Heri, and Bachtiar, "The flame characteristics of the biogas has produced through the digester method with various starters," IOP Conf. Ser. Mater. Sci. Eng., vol. 299, p. 12091, 2018, doi: $10.1088 / 1757-899 x / 299 / 1 / 012091$.

[4] T. M. Gantina, P. Iriani, Maridjo, and C. K. Wachjoe, "Biogas purification using water scrubber with variations of water flow rate and biogas pressure," J. Phys. Conf. Ser., vol. 1450, no. 1, 2020, doi: 10.1088/1742-6596/1450/1/012011.

[5] M. B. Kulkarni and P. M. Ghanegaonkar, "Hydrogen sulfide removal from biogas using chemical absorption technique in packed column reactors," Glob. J. Environ. Sci. Manag., vol. 5, no. 2, pp. 155-166, 2019, doi: 10.22034/gjesm.2019.02.02.

[6] R. K. Kashyap, P. Chugh, and T. Nandakumar, "Opportunities \& Challenges in Capturing Landfill Gas from an Active and Un-scientifically Managed Land Fill Site - A Case Study," Procedia Environ. Sci., vol. 35, pp. 348-367, 2016, doi: 10.1016/j.proenv.2016.07.015.

[7] A.-A. S. M. Magomnang and P. E. P. Villanueva, "Utilization of the Uncoated Steel Wool for the Removal of Hydrogen Sulfide from Biogas," Int. J. Mining, Metall. Mech. Eng., vol. 3, no. 3, pp. 108-111, 2015.

[8] U. Riyadi, G. A. Kristanto, and C. R. Priadi, "Utilization of steel wool as removal media of hydrogen sulfide in biogas," IOP Conf. Ser. Earth Environ. Sci., vol. 105, no. 1, p. 012026, Jan. 2018, doi: 10.1088/17551315/105/1/012026.

[9] P. Kadam, J. P. Shete, and M. Student, "Experimental Study of Heat Transfer Characteristics and Thermal Efficiency of Different Cooking Pots," Int. J. Sci. Dev. Res., vol. 2, no. 12, pp. 121-130, 2017, [Online]. Available: www.ijsdr.org.

[10]Rani, "From Water Boiling Test to Water Heating Test," Indonesian Clean Stove Initiative, 2016. https://www.diandesa.org/daily-blog-project-news/from-water-boiling-test-to-water-heating-test-case-study-ofindonesia/ (accessed Apr. 02, 2021).

[11]EURAMET, "CG 8 Guidelines on the Calibration of Thermocouples," vol. 3.1, no. 8, 2020. 